\title{
Tingkat Risiko Kesehatan Kapal di Pelabuhan Belawan Medan dan Faktor yang Mempengaruhi
}

\author{
Ovra $^{1}$, Lukman $^{2}$, Vierto $^{3}$ \\ Program Studi IImu Kesehatan Masyarakat, Universitas Sari Mutiara Indonesia \\ J. Kapten Muslim No 79, Medan 20123 \\ Email: ${ }^{1}$ tievemarvel@gmail.com, 2lukman_23@gmail.com, ${ }^{3}$ vierto07@gmail.com
}

\begin{abstract}
Abstrak
Sanitasi adalah suatu usaha pencegahan penyakit dengan melenyapkan atau mengendalikan faktor - faktor risiko lingkungan yang merupakan mata rantai penularan penyakit. Sanitasi kapal berlaku untuk semua jenis kapal baik kapal penumpang, maupun kapal barang baik dari dalam maupun luar negeri. Pemeriksaan sanitasi kapal dimaksudkan untuk pengeluaran sertifikat sanitasi guna memperoleh Surat Izin Kesehatan Berlayar (SIKB). Untuk mengetahui faktor - faktor yang berhubungan dengan tingkat risiko kesehatan kapal, telah dilakukan penelitian terhadap 89 kapal yang berlabuh di Pelabuhan Belawan dengan rancangan penelitian cross sectional. Hasil penelitian menunjukkan ada hubungan antara pengetahuan $A B K$ ( $p$. Value $=0,049$ ), sikap $A B K$ (p. Value $=0,045$ ), penerapan SOP $(p$. Value $=0,000)$, kepemimpinan nakhoda $(p$. Value $=0,005)$, peran institusi KKP $(p$. Value $=0,02 \mathrm{I})$, tindakan penyehatan alat angkut ( $\mathrm{p}$. Value $=0,00 \mathrm{I}$ ), dengan tingkat risiko kesehatan kapal. Uji multivariat menyatakan bahwa faktor penerapan SOP sangat dominan berhubungan dengan tingkat risiko kesehatan kapal dengan nilai ( $\mathrm{p}$. Value = 0,002; $O R=66.6079$ ). Perlu Pengawasan rutin sanitasi kapal agar dilaksanakan secara terencana dan tegas terhadap sanita sikapal yang bersandar di Pelabuhan Belawan, sehingga tidak ditemukan kapal dengan sanitasi kapal kategori risiko tinggi dan melaksanakan evaluasi secara berkesinambungan terhadap kepemilikan sertifikat sanitasi kapal pada seluruh kapal secara berkala.
\end{abstract}

Kata kunci : Penerapan SOP, Tingkat Risiko, Kesehatan Kapal

\begin{abstract}
Sanitation is an attempt to forestall disease by eliminating ort controlling environmental risk factors as the link of infection Ship sanitation includes all types of ship : passenger ships and freighters, either domestis or foreign. The purpose of checking ship sanitation certificates in order to obtain SIKB (Sailing Health Permit). The objective of the research was to find out some factors which were correlated with the level of risk for the health of ships at Belawan Harbor. There were 89 ships which had been studied at Belawan harbor, using cross sectional design. The result of the research showed that there was the correlation of the knowledge of the crew ( $p$-value $=0.049)$, attitude of the crew ( $p$-value $=0.045)$, SOP implementation $(p$ value $=0.000$ ), leadership of the ship's captains ( $p$-value $=0.005$ ), the role of KKP institution ( $p$-value $=0.02 I$ ), and health action for transportation ( $p$-value $=0.00 \mathrm{I}$ ) with the level of risk for the health of ships. The result of multivariate analysis showed that the variable of SOP implementation had the most dominant correlation with the level of risk for health of ships ( $p$-value $=0.002 ; O R=66.6079)$. It is recomended that routine supervision on ship sanitation be planed firmly, especially on moored ships in Belawan harbor so that there will be no more high risk. Sustainable evaluation on the ownership of sanitation certificates of all moored ship should be done regularly.
\end{abstract}

Keywords : SOP Implementation, Level Of Risk, Ship Health 


\section{Pendahuluan}

Pelabuhan merupakan salah satu aset penting suatu daerah yang berfungsi sebagai tempat berlabuhnya kapal sekaligus sebagai tempat untuk melakukan kegiatan bongkar muat barang, kebutuhan masyarakat dan industri serta sebagai tempat pelayanan penyeberangan penumpang baik domestik maupun internasional. Pada saat ini pelabuhan tidak hanya berfungsi sebagai pintu keluar masuk barang, lebih dari itu sudah merupakan sebagai sentra industri, pusat perdagangan dan pariwisata yang banyak menyerap tenaga kerja. Mobilisasi yang tinggi dari aktivitas di pelabuhan, secara otomatis penyebaran penyakit akan semakin cepat dan beragam, sehingga akan berpotensi menimbulkan dampak yang merugikan bagi pencapaian tujuan pembangunan kesehatan nasional.

Kapal adalah semua alat pengangkut, termasuk milik angkatan bersenjata dan yang dapat berlayar. Dengan demikian kapal harus terbebas dari faktor risiko lingkungan dengan cara mempertahankan kondisi kesehatan kapal sehingga tidak dijadikan tempat berkembangnya penyakit dan vektor penular penyakit. Sanitasi kapal merupakan salah satu usaha yang ditujukan terhadap faktor risiko lingkungan di kapal untuk memutuskan mata rantai penularan penyakit guna memelihara dan mempertinggi derajat kesehatan. Sanitasi kapal mencakup seluruh aspek penilaian kompartemen kapal antara lain dapur, ruang penyediaan makanan,palka, gudang, kamar anak buah kapal, penyediaan air bersih, dan penyajian makanan serta pengendalian vektor penular penyakit atau rodent. $^{1}$

Sanitasi adalah suatu usaha pencegahan penyakit dengan melenyapkan atau mengendalikan faktor - faktor risiko lingkungan yang merupakan mata rantai penularan penyakit.Sanitasi kapal berlaku untuk semua jenis kapal baik kapal penumpang, maupun kapal barang baik dari dalam maupun luat negeri.Pemeriksaan sanitasi kapal dimaksudkan untuk pengeluaran sertifikat sanitasi guna memperoleh Surat Izin Kesehatan Berlayar (SIKB). Hasil pemeriksaan dinyatakan berisiko tinggi atau risiko rendah, jika kapal yang diperiksa dinyatakan risiko tinggi maka diterbitkan Ship Sanitation Control Certificate (SSCC) setelah dilakukan tindakan sanitasi dan apabila faktor risiko rendah diterbitkan Ship Sanitation Exemption Control Certificate (SSCEC), dan pemeriksaan dilakukan dalam masa waktu enam bulan sekali. ${ }^{2}$

Adapun institusi yang memiliki kewenangan untuk melakukan pemeriksaan adalah Kantor Kesehatan Pelabuhan (KKP). Menurut Permenkes No. 356/Menkes/IV/2008, bahwa KKP mempunyai tugas melaksanakan pencegahan masuk dan keluarnya penyakit karantina dan penyakit menular potensial wabah, kekarantinaan, pelayanan kesehatan terbatas di wilayah kerja Pelabuhan/ Bandara dan Lintas Batas, serta pengendalian dampak kesehatan lingkungan. Selain itu salah satu fungsi penting KKP adalah pelaksanaan pengamatan penyakit karantina dan penyakit menular potensial wabah nasional sesuai penyakit yang berkaitan dengan lalulintas internasional, pelaksanaan pengawasan kesehatan alat angkut dan pelaksanaan pengendalian risiko lingkungan Pelabuhan / Bandara dan Lintas Batas Darat Kantor Kesehatan Pelabuhan memiliki peran yang sangat penting dalam mewujudkan kondisi pelabuhan yang bebas dari penularan penyakit. Dengan adanya Peraturan Kesehatan Internasional/International Health Regulation (IHR) tahun 2005 untuk mengatur tata cara dan pengendalian penyakit, baik yang menular maupun yang tidak menular, maka Kantor Kesehatan Pelabuhan harus kuat dan prima dalam melaksanakan cegah tangkal penyakit karantina dan penyakit menular. ${ }^{3}$

Tujuan pemeriksaan sanitasi kapal dimaksudkan agar kapal bebas dari ancaman penyakit yang berpotensi wabah, 
dan mencegah penularan penyakit menular, serta menciptakan suasana nyaman dan aman bagi penumpang, ABK maupun nakhoda kapal. $^{2}$ Upaya sanitasi kapal merupakan tanggung jawab pemilik kapal melalui nakhoda kapal dan anak buah kapal.ABK bertanggung jawab terhadap kebersihan kapal dan sarana lainnya yang mendukung sanitasi kapal.Sedangkan fungsi Nahkoda kapal adalah sebagai pemimpin dan pengendali keseluruhan dari pelaksanaan sanitasi kapal.Pemilik kapal wajib menyertakan Standart Operational Prosedure (SOP) sanitasi kapal yang mengacu pada IHR dan ketentuan lainnya. ${ }^{1}$

Nahkoda kapal bertanggung jawab terhadap keamanan kapal dari sumber panyakit dan melaporkan dalam bentuk form MDH (Maritime Declaration of Health) kepada otoritas kesehatan pelabuhan setiap masuk wilayah suatu negara. Sanitasi kapal merupakan salah satu bagian integral dari perilaku kesehatan terhadap sanitasi. Faktor enabling mencakup biaya, waktu, dan sarana, sedangkan faktor reinforcing mencakup dukungan petugas kesehatan, dan implementasi kebijakan sanitasi kapal. ${ }^{1}$ Berdasarkan data Dirjen Pemberantasan Penyakit dan Penyehatan Lingkungan selama kurun waktu 2005-2008 jumlah kapal yang sudah mendapatkan SSCEC cenderung meningkat. Tahun 2005 terdapat 2.756 unit kapal (70,6\%) dari 3.906 kapal yang diperiksa menjadi 2903 (73,3\%) dari 3961 kapal yang diperiksa pada tahun 2006. Tahun 2007 menurun menjadi 949 kapal (23,3\%) dari 4071 kapal yang diperiksa dan tahun 2008 meningkat menjadi 2.846 (69,6\%) dari 4092 kapal yang diperiksa. ${ }^{3}$ Keadaan ini menunjukkan bahwa pemeriksaan sanitasi kapal menjadi agenda rutin dan tugas penting bagi KKP, sehingga kapal-kapal yang berlabuh di seluruh pelabuhan di Indonesia terjamin sanitasi kapalnya dan bebas dari sumber penularan penyakit khususnya penyakit yang berpotensi wabah. Pemahaman SOP yang baik cenderung mempunyai sanitasi kapal yang baik dibandingkan dengan pemahaman SOP oleh ABK yang tidak baik. ${ }^{4}$ Tindakan hapus tikus di kapal merupakan salah satu bentuk tindakan sanitasi kapal, bahkan merupakan item penting dalam MDH. Salah satu pertanyaan dalam MDH adalah tentang adanya indikasi penyakit pes baik yang timbul diantara ABK maupun diantara tikus.Kepemilikan SSCEC juga sangat memperhatikan Surat Keterangan Hapus Tikus (SKHT), artinya bahwa kepemilikan SSCEC mutlak harus memperhatikan sanitasi kapal secara keseluruhan. ${ }^{5}$

Pelabuhan Domestik Gresik menemukan bahwa persoalan sanitasi pelabuhan mencakup sanitasi kapal masih sangat rendah.Kontribusi sanitasi kapal sangat besar terhadap perwujudan sanitasi pelabuhan secara keseluruhan. Cakupan sanitasi kapal hanya 32,6\% dari 3091 kapal yang bersandar. Rendahnya sanitasi kapal tersebut mengindikasikan minimnya penyediaan air bersih dan sanitasi dok kapal, serta masih ditemukannya vektor atau rodent dalam kapal meskipun dalam jumlah yang relatif kecil. ${ }^{6}$

Salah satu upaya untuk meningkatkan sanitasi kapal adalah melakukan pengelolaan sampah kapal dengan menetapkan SOP pengelolaan sampah.Pada kapal penumpang perlu diciptakan sanitasi kapal yang benar, selain itu perlu pemenuhan indikator sanitasi lainnya seperti penyediaan air bersih, dan pengendalian vektor atau rodent.Pelabuhan Belawan merupakan salah satu pelabuhan yang padat melayani pelayaran domestik dan internasional, khususnya pelayanan kargo. Berdasarkan data KKP Kelas I Medan Tahun 2016 jumlah kapal yang bersandar di pelabuhan Belawan baik domestik maupun international sebanyak 3478 kapal yang terdiri atas kapal penumpang, kapal kargo, kapal tangki, tugboat. Berdasarkan data tersebut masingmasing mempunyai perbedaan sanitasi baik sanitasi berisiko tinggi maupun sanitasi berisiko rendah. Hasil pemeriksaan sanitasi kapal tahun 2016, menunjukkan jumlah kapal yang sudah memiliki 
sertifikat SSCEC (risiko rendah) sebanyak 3286 kapal (94,47\%), dan 192 kapal (5.53\%) memperoleh sertifikat SSCC (risiko tinggi) dari 3478 kapal yang diperiksa. Hal ini menunjukkan bahwa kapal yang berlabuh di pelabuhan Belawan masih berisiko rendah, sehingga perlu dilakukan upaya strategis untuk meningkatkan cakupan sanitasi kapal.

Berdasarkan hasil pemeriksaan sanitasi kapal tahun 2016 yang dilakukan oleh petugas KKP Kelas I Medan, diketahui bahwa sanitasi beresiko tinggi pada kapal diindikasikan dari keadaan sanitasi kamar ABK, ketersediaan tempat pembuangan sampah, dan sanitasi dapur serta keberadaan vector dan binatang penular penyakit. Keadaan tersebut dipengaruhi oleh faktor perilaku ABK yang tidak menjaga kebersihan ruangan kamar atau dapur. Berdasarkan latar belakang tersebut, peneliti tertarik untuk meneliti faktor-faktor apa yang berhubungan dengan tingkat risiko kesehatan kapal dalam dan luar di KKP Kelas I Medan Tahun 2017.

\section{Metode}

Jenis penelitian adalah merupakan penelitian observasional dengan pendekatan cross sectional yaitu suatu penelitian di mana variabel-variabel yang termasuk faktor-faktor tingkat risiko kapal dan variabel-variabel yang termasuk efek diobservasi sekaligus dilakukan pada waktu yang sama.Penelitian di lakukan di Kantor Kesehatan Pelabuhan Kelas I Medan.Penelitian dilakukan pada pada Bulan Pebruari s.d Juni 2017 atau sampai data yang diperlukan telah lengkap.

\section{Hasil}

Dari tabel di atas menunjukkan bahwa kategori baik sebanyak 85 (95,5\%), kategori sikap sebanyak 80 (89,9\%), kategori penerapan SOP baik sebanyak 70 orang (78,7\%), kategori Kepemimpinan Nakhoda pada kategori baik sebanyak 80 (89,9\%, Peran Serta Institusi KKP pada kategori baik sebanyak 82 (92,1\%), Tindakan Penyehatan Alat Angkut kategori pernah 86 (96,6\%), Tingkat Risiko Kesehatan Kapal kategori Rendah sebanyak $80(89,9)$.

Tabel 1. Analisis Univariat

\begin{tabular}{llll}
\hline Variabel & Kategori & $\mathbf{n}$ & $\mathbf{\%}$ \\
\hline Pengetahuan & Kurang Baik & 4 & 4,5 \\
& Baik & 85 & 95,5 \\
Sikap & Kurang Baik & 9 & 10,1 \\
& Baik & 80 & 89,9 \\
Penerapan SOP & Kurang Baik & 19 & 21,3 \\
& Baik & 70 & 78,7 \\
Kepemimpinan & Kurang Baik & 9 & 10,1 \\
Nakhoda & Baik & 80 & 89,9 \\
Peran Serta Institusi & Tidak Ada & 7 & 7,9 \\
KKP & Ada & 82 & 92,1 \\
Tindakan Penyehatan & Tidak & 3 & 3,4 \\
Alat Angkut & Pernah & & \\
& Pernah & 86 & 96,6 \\
Tingkat Risiko & Tinggi & 9 & 10,1 \\
Kesehatan Kapal & Rendah & 80 & 89,9 \\
\hline
\end{tabular}

\section{Analisis Bivariat}

Hasil uji statistik dengan menggunakan uji chi-square diperoleh bahwa nilai $\mathrm{p}=0.049(\mathrm{p}<0,05)$ hal ini menunjukkan bahwa ada hubungan antara pengetahuan $\mathrm{ABK}$ dengan tingkat risiko kesehatan kapal dengan nilai $\mathrm{OR}=.6,071$, artinya ABK yang memiliki tingkat pengetahuan yang baik akan memiliki tingkat risiko kesehatan kapal yang rendah sebesar 6,071 kali bila di bandingkan dengan ABK yang memiliki tingkat pengetahuan yang kurang baik. Hasil uji statistik dengan menggunakan uji chisquare diperoleh bahwa nilai $\mathrm{p}=0.045$ (p $<0,05$ ) hal ini menunjukkan bahwa ada hubungan antara sikap ABK dengan tingkat risiko kesehatan kapal dengan nilai OR $=.4,444$ artinya ABK yang memiliki tingkat sikap yang baik akan memiliki tingkat risiko kesehatan kapal yang rendah sebesar 4,444 kali bila di bandingkan dengan ABK yang memiliki timgkat sikap yang kurang baik. 
Tabel 2. Analisis Bivariat

\begin{tabular}{|c|c|c|c|c|c|c|c|c|}
\hline \multirow{3}{*}{ Variabel } & \multirow{3}{*}{ Kategori } & \multicolumn{4}{|c|}{ Risiko Kesehatan Kapal } & \multirow{3}{*}{ PR } & \multirow{3}{*}{$\begin{array}{c}\mathbf{P} \\
\text { Value }\end{array}$} & \multirow{3}{*}{$95 \% \mathrm{CI}$} \\
\hline & & \multicolumn{2}{|c|}{ Tinggi } & \multicolumn{2}{|c|}{ Rendah } & & & \\
\hline & & n & $\%$ & $\mathbf{n}$ & $\%$ & & & \\
\hline \multirow[t]{2}{*}{ Pengetahuan } & Kurang Baik & 2 & 50 & 2 & 50 & \multirow{3}{*}{6,071} & \multirow{3}{*}{0,049} & \multirow{2}{*}{ 1,811-20,359 } \\
\hline & Baik & 7 & 8,2 & 78 & 91,8 & & & \\
\hline \multirow[t]{2}{*}{ Sikap } & Kurang Baik & 3 & 33,3 & 6 & 66,7 & & & \\
\hline & Baik & 6 & 7,5 & 74 & 92,5 & 4,444 & 0.045 & $1,335-14,792$ \\
\hline \multirow[t]{2}{*}{ Penerapan SOP } & Kurang Baik & 7 & 36,8 & 12 & 63,2 & \multirow{2}{*}{12,895} & \multirow{2}{*}{0.000} & \multirow{2}{*}{$2,914-57,068$} \\
\hline & Baik & 2 & 2,9 & 68 & 97,1 & & & \\
\hline Kepemimpinan & Kurang Baik & 4 & 44,4 & 5 & 55,6 & \multirow{2}{*}{7,111} & \multirow{2}{*}{0.005} & \multirow{2}{*}{ 2,914-57,068 } \\
\hline Nakhoda & Baik & 5 & 6,3 & 75 & 93,8 & & & \\
\hline Peran Serta & Kurang Baik & 3 & 42,9 & 4 & 57,1 & \multirow{2}{*}{5,857} & \multirow{2}{*}{0.021} & \multirow{2}{*}{ 2,914-57,068 } \\
\hline Instansi KKP & Baik & 6 & 7,3 & 76 & 92,7 & & & \\
\hline Peran Serta & Kurang Baik & 3 & 100 & 0 & 0 & \multirow{2}{*}{14,333} & \multirow{2}{*}{0,001} & \multirow{2}{*}{ 2,914-57,068 } \\
\hline Instansi KKP & Baik & 6 & 7 & 80 & 93 & & & \\
\hline
\end{tabular}

Hasil uji statistik dengan menggunakan uji chi-square diperoleh bahwa nilai $\mathrm{p}=0.000(\mathrm{p}<0,05)$ hal ini menunjukkan bahwa ada hubungan antara penerapan SOP dengan tingkat risiko kesehatan kapal dengan nilai OR $=.12,895$ artinya penerapan SOP yang baik akan memiliki tingkat risiko kesehatan kapal yang rendah sebesar 12,895 kali bila di bandingkan dengan penerapan SOP yang kurang baik.Hasil uji statistik dengan menggunakan uji chi-square diperoleh bahwa nilai $\mathrm{p}=0.005(\mathrm{p}<0,05)$ hal ini menunjukkan bahwa ada hubungan antara kepemimpinan nakhoda dengan tingkat risiko kesehatan kapal dengan nilai OR =.7,111 artinya kepemimpinan nakhoda yang baik akan memiliki tingkat risiko kesehatan kapal yang rendah sebesar 7,111 bila di bandingkan dengan kepemimpinan nakhoda yang kurang baik.Hasil uji statistik dengan menggunakan uji chisquare diperoleh bahwa nilai $\mathrm{p}=0.021 \mathrm{p}$ $<0,05$ ) hal ini menunjukkan bahwa ada hubungan antara peran institusi KKP dengan tingkat risiko kesehatan kapal dengan nilai $\mathrm{OR}=.5,857$ artinya bila ada peran institusi KKP akan memiliki tingkat risiko kesehatan kapal yang rendah sebesar 5,857 bila di bandingkan dengan peran serta institusi yang tidak ada.Hasil uji statistik dengan menggunakan uji chisquare diperoleh bahwa nilai $\mathrm{p}=0.001 \mathrm{p}$ $<0,05$ ) hal ini menunjukkan bahwa ada hubungan antara tindakan penyehatan alat angkut dengan tingkat risiko kesehatan kapal dengan nilai OR $=.14,333$ artinya apabila pada alat angkut pernah dilaksanakan tindakan penyehatan alat angkut akan memiliki tingkat risiko kesehatan kapal yang rendah sebesar 14,333 bila di bandingkan pada alat angkut yang tidak pernah dilakukan tindakan penyehatan alat angkut.

\section{Analisis Multivariat}

Tabel 3. Kandidat Analisis Uji Multivariat

\begin{tabular}{lll}
\hline Variabel Penelitian & P. Value & PR \\
\hline Pengetahuan ABK & 0,049 & 6,071 \\
Sikap ABK & 0,045 & 4,444 \\
$\begin{array}{l}\text { Penerapan SOP } \\
\text { Kepemimpinan }\end{array}$ & 0,000 & 12,895 \\
$\begin{array}{l}\text { Nakhoda } \\
\text { Peran Serta Intitusi }\end{array}$ & 0,005 & 7,111 \\
KKP Penehatan & 0,001 & 5,857 \\
Tindakan Penyeh & \\
Alat Angkut & & 14,333 \\
\hline
\end{tabular}

Dari tabel 3 diatas dapat dilihat bahwa penerapan SOP dengan nilai $\mathrm{p}=$ 0,016 dengan nilai OR 35,39. Kepemimpinan nakhoda dengan nilai $\mathrm{p}=$ 0,120 dengan nilai $\mathrm{OR}=7,72$, peran serta institusi KKP dengan nilai $\mathrm{p}=0,823$ dengan nilai $\mathrm{OR}=1,53$. Pengetahuan $\mathrm{ABK}$ dengan nilai $\mathrm{p}=0,146$ dengannilai $\mathrm{OR}=$ 12,35dan sikap $\mathrm{ABK}$ dengan nilai $\mathrm{p}=$ 0,116 dengan niali $\mathrm{OR}=16,06$. 
Tabel 4. Analisis Multivariat Tahap Awal Faktor-Faktor Yang Berhubungan Dengan Tingkat Risiko Kesehatan Kapal Di Kantor Kesehatan Pelabuhan Kelas I Tahun 2017

\begin{tabular}{|c|c|c|c|c|c|}
\hline Variabel & & Odds Ratio & $\begin{array}{l}\text { Std. } \\
\text { Error }\end{array}$ & P value & $95 \%$ CI \\
\hline Penerapan SOP & & 35,39 & 52,32 & 0,016 & $1,953-641,41$ \\
\hline $\begin{array}{l}\text { Kepemimpinan } \\
\text { Kapal }\end{array}$ & Nakhoda & 7,72 & 10,14 & 0,120 & $0,587-101,46$ \\
\hline Peran Serta Institusi & & 1,53 & 2,96 & 0,823 & $0,035-67,09$ \\
\hline Pengetahuan ABK & & 12,35 & 21,36 & 0,146 & $0,417-365,79$ \\
\hline Sikap ABK & & 16,06 & 28,42 & 0,116 & $0,501-514,59$ \\
\hline
\end{tabular}

Table 5. Analisis Multivariat Tahap Akhir Faktor-Faktor Yang Berhubungan Dengan Tingkat Risiko Kesehatan Kapal Di Kantor Kesehatan Pelabuhan Kelas I Tahun 2017

\begin{tabular}{lllll}
\hline Variabel & Odds Ratio & $\begin{array}{l}\text { Std. } \\
\text { Error }\end{array}$ & P value & 95\% CI \\
& \multicolumn{5}{c}{} & \\
\hline Penerapan SOP & 66,61 & 91,19 & 0,002 & $4,55-974,75$ \\
Peran Serta Institusi & 29,15 & 42,09 & 0,020 & $1,72-494.00$ \\
Sikap ABK & 21,41 & 29,61 & 0,027 & $1,42-321,81$ \\
\hline
\end{tabular}

Untuk mengetahui faktor yang paling dominan berhubungan dengan tingkat risiko kesehatan kapal di lanjutkan kembali dengan melakukan uji tahap ahkir (Tabel 5). Tabel 5 menunjukkan bahwa faktor yang paling dominan berhubungan dengan tingkat risiko kesehatan adalah faktor penerapan SOP dengan nilai $\mathrm{p}=0,002$ dengan nilai $\mathrm{OR}=66,61$ dan diikuti dengan faktor Peran Serta Institusi dengan nilai $\mathrm{p}=0,020$ dengan niali $\mathrm{OR}=29,15$

\section{Pembahasan}

\section{Hubungan Pengetahuan ABK DenganTingkat Risiko Kesehatan Kapal}

Berdasarkan tabulasi silang antara tingkat pengetahuan dengan tingkat risiko kesehatan kapal dapat dilihat bahwa dari 4 orang ABK yang memiliki pengetahuan yang kurang baik tentang tingkat risiko kesehatan kapal masing-masing 2 orang (50,0\%) memiliki tingkat risiko kapal yang tinggi dan rendah. Dari 85 orang $A B K$ yang memiliki pengetahuan baik, 7 kapal $(8,2 \%)$ diantaranya memiliki tingkat risiko kapal yang tinggi dan 78 kapal (91,8\%) memiliki tingkat risiko kesehatan kapal yang rendah.
ABK mayoritas (85\%) memiliki tingkat pengetahuan yang baik terhadap tingkat sanitasi kapal, berdasarkan hasil penelitian Saifullah menyatakan juga bahwa 65\% kapal yang berlabuh di Pelabuhan Lhoksemawe memiliki sanitasi yang baik. ${ }^{4}$

Hasil uji statistik dengan menggunakan uji chi-square diperoleh bahwa nilai $\mathrm{p}=0.049(\mathrm{p}<0,05)$ hal ini menunjukkan bahwa ada hubungan antara pengetahuan $\mathrm{ABK}$ dengan tingkat risiko kesehatan kapal dengan nilai $\mathrm{OR}=.6,071$, artinya ABK yang memiliki tingkat pengetahuan yang baik akan memiliki tingkat risiko kesehatan kapal yang rendah sebesar 6,071 kali bila di bandingkan dengan $\mathrm{ABK}$ yang memiliki tingkat pengetahuan yang kurang baik.

\section{Hubungan Sikap ABK Dengan Tingkat Risiko Kesehatan Kapal}

Berdasarkan tabulasi silang antara sikap ABK dengan tingkat risiko kesehatan kapal dapat dilihat bahwa dari 9 orang ABK yang memiliki sikapyang kurang baik tentang tingkat risiko kesehatan kapal, 6 kapal $(66,7 \%)$ memiliki tingkat risiko kapal yang rendah dan 3 orang $(33,3)$ kapal 
memiliki tingkat risiko kapal yang tinggi. Dari 80 orang ABK yang memiliki sika baik, 6 kapal (7,5\%) diantaranya memiliki tingkat risiko kapal yang tinggidan 74 kapal (92,5\%) memiliki tingkat risiko kesehatan kapal yang rendah.

Sikap (attitude) merupakan reaksi atau respon yang masih tertutup dari seseorang terhadap suatu stimulus atau objek. Manifestasi sikap itu tidak dapat langsung dilihat, tetapi hanya dapat langsung ditafsirkan terlebih dahulu dari perilaku yang tertutup. Sikap belum merupakan suatu tindakan atau aktivitas, akan tetapi merupakan predisposisi tindakan suatu perilaku. Sikap masih merupakan reaksi tertutup, bukan merupakan reaksi terbuka atau tingkah laku yang terbuka. Sikap merupakan kesiapan untuk bereaksi terhadap objek di lingkungan tertentu sebagai penghayatan terhadap objek. ${ }^{7}$

Hasil uji statistik dengan menggunakan uji chi-square diperoleh bahwa nilai $\mathrm{p}=0.045(\mathrm{p}<0,05)$ hal ini menunjukkan bahwa ada hubungan antara sikap ABK dengan tingkat risiko kesehatan kapal dengan nilai OR $=.4,444$ artinya ABK yang memiliki tingkat sikap yang baik akan memiliki tingkat risiko kesehatan kapal yang rendah sebesar 4,444 kali bila di bandingkan dengan ABK yang memiliki timgkat sikap yang kurang baik.

\section{Hubungan Penerapan SOP Dengan Tingkat Risiko Kesehatan Kapal}

Berdasarkan tabulasi silang antara penerapan SOP dengan tingkat risiko kesehatan kapal dapat dilihat bahwa dari 19 orang ABK yang memiliki penerapan SOP yang kurang baik tentang tingkat risiko kesehatan kapal 7 kapal (36,8\%) memiliki tingkat risiko kesehatan kapal yang tinggi dan 12 kapal (63,5\%) memiliki tingkat risiko kapal yang rendah. Dari 68 orang ABK yang memiliki penerapan SOP yang baik, 2kapl (2,9\%) diantaranya memiliki tingkat risiko kesehatan kapal yang tinggi dan 68 kapal (97,1\%) memiliki tingkat risiko kesehatan kapal yang rendah. $\begin{array}{ccr}\text { Hasil } & \text { Penelitian } & \text { Saifullah } \\ \text { menunjukkan } & \text { mayoritas } & \text { responden }\end{array}$ menyatakan tidak tersedia SOP untuk sanitasi kapal yaitu sebanyak 32 orang (60,4\%), dan mayoritas juga menyatakan SOP tidak sesuai dengan IHR yaitu sebanyak 32 orang $(60,4 \%)$, mayoritas responden sudah melakukan tugas sesuai SOP yaitu sebanyak 27 orang (50,9\%), mayoritas respnden juga sudah melakukan upaya sanitasi dapur kapal yaitu sebanyak 26 orang (49,1\%). Namun mayoritas responden tidak melakukan upaya sanitasi kamar ABK yaitu sebanyak 33 orang (62,3\%), mayoritas juga tidak melakukan upaya sanitasi kamar mandi yaitu sebanyak 29 orang (54,7\%), mayoritas responden juga belum melakukan upaya sanitasi penyimpanan makanan yaitu sebanyak 40 (75,5\%), dan mayoritas responden juga menyatakan bahwa manajemen tidak memberikan sanksi bagi ABK yang tidak menerapkan SOP yaitu sebanyak 39 orang (73,6\%).

Hasil uji statistik dengan menggunakan uji chi-square diperoleh bahwa nilai $\mathrm{p}=0.000(\mathrm{p}<0,05)$ hal ini menunjukkan bahwa ada hubungan antara penerapan SOP dengan tingkat risiko kesehatan kapal dengan nilai OR $=.12,895$ artinya penerapan SOP yang baik akan memiliki tingkat risiko kesehatan kapal yang rendah sebesar 12,895 kali bila di bandingkan dengan penerapan SOP yang kurang baik.

Standar prosedur operasional, dengan tingkat sanitasi kapal sangat berhubungan dengan nilai $\mathrm{p}=0,21$, beliau jugja menyatakan bahwa dengan adanya SOP setiap ABK akan mengacu kepada SOP dan tidak akan menyimpang dari prosedur yang telah di tetapkan. Setiap ABK akan melaksanakan tugasnya sesuai dengan job yang telah di tentukan oleh nakhoda yang disesuaikan dengan tugas dan tanggung jawab masing-masing dari Anak Buah Kapal.Berdasarkan variabel penerapan SOP, diketahui proporsi kapal denganpenerapan SOP kategori baik 100\% mendapatkan sertifikat SSCEC, demikian 
jugadengan penerapan SOP kategori kurang 75,8\% mendapatkan sertifikat SSCC. Hasilstatistik dengan uji Exact Fisher's Test menunjukkan bahwa penerapan SOP mempunyai hubungan signifikan terhadap kepemilikan sertifikasi sanitasi kapaldengan nilai probabilitas $0,019(p<0,05){ }^{4}$

\section{Hubungan Kepemimpinan Nakhoda Dengan Tingkat Risiko Kesehatan Kapal}

Berdasarkan tabulasi silang antara kepemimpinan nakhoda dengan tingkat risiko kesehatan kapal dapat dilihat bahwa dari 9 orang ABK yang memiliki kepemimpinan nakhoda yang kurang baik tentang tingkat risiko kesehatan kapal 4 kapal (44,4\%) memiliki tingkat risiko kesehatan kapal yang tinggi dan 5 kapal (55,6\%) memiliki tingkat risiko kapal yang rendah. Dari 80 orang $A B K$ yang memiliki kepemimpinan nakhoda yang baik, 5 kapal (6,3\%) diantaranya memiliki tingkat risiko kesehatan kapal yang tinggidan 75 kapal (93,7\%) memiliki tingkat risiko kesehatan kapal yang rendah.

Manajemen perencanaan sanitasi termasuk SOP dapat menjamin keamanan sistem operasional sanitasi dikapal. Pencatatan dan dokumentasi yang tepat dapat menjadi bukti pendukung pada saat audit dibutuhkan, melihat ukuran kecendrungan dan yang terpenting terhindar dari masalah di pengadilan. Nahkoda kapal bertanggung jawab terhadap keamanan kapal dari sumber panyakit dan melaporkan dalam bentuk form MDH (MaritimeDeclaration of Health) kepada otoritas kesehatan pelabuhan setiap masuk wilayah suatu negara. $^{2}$

Hasil uji statistik dengan menggunakan uji chi-square diperoleh bahwa nilai $\mathrm{p}=0.005(\mathrm{p}<0,05)$ hal ini menunjukkan bahwa ada hubungan antara kepemimpinan nakhoda dengan tingkat risiko kesehatan kapal dengan nilai OR $=.7,111$ artinya kepemimpinan nakhoda yang baik akan memiliki tingkat risiko kesehatan kapal yang rendah sebesar 7,111 bila di bandingkan dengan kepemimpinan nakhoda yang kurang baik.

\section{Hubungan Peran Institusi KKP Dengan Tingkat Risiko Kesehatan Kapal}

Dari bahwa dari 7 orang ABK yang menyatakan tidak ada peran institusi KKP dalam pengawasan kesehatan kapal, 3 kapal (42,9\%) memiliki tingkat risiko kesehatan kapal yang tinggi dan 4 kapal (55,6\%) memiliki tingkat risiko kapal yang rendah. Dari 82 orang ABK yang menyatakan ada peran institusi KKP dalam pengawasan kesehatan kapal, 6 kapal (7,3\%) diantaranya memiliki tingkat risiko kesehatan kapal yang tinggidan 76 kapal (92,7\%) memiliki tingkat risiko kesehatan kapal yang rendah

Menurut Permenkes No 356/Menkes/IV/2008, bahwa KKP mempunyai tugas melaksanakan pencegahan masuk dan keluarnya penyakit karantina dan penyakit menular potensial wabah, kekarantinaan, pelayanan kesehatan terbatas di wilayah kerja Pelabuhan/ Bandara dan Lintas Batas, serta pengendalian dampak kesehatan lingkungan. Selain itu salah satu fungsi penting KKP adalah pelaksanaan pengamatan penyakit karantina dan penyakit menular potensial wabah nasional sesuai penyakit yang berkaitan dengan lalulintas internasional, pelaksanaan pengawasan kesehatan alat angkut dan pelaksanaan pengendalian risiko lingkungan Pelabuhan/Bandara dan Lintas Batas Darat. $^{3}$

Hasil uji statistik dengan menggunakan uji chi-square diperoleh bahwa nilai $\mathrm{p}=0.021(\mathrm{p}<0,05)$ hal ini menunjukkan bahwa ada hubungan antara peran institusi KKP dengan tingkat risiko kesehatan kapal dengan nilai $\mathrm{OR}=.5,857$ artinya bila ada peran institusi KKP akan memiliki tingkat risiko kesehatan kapal yang rendah sebesar 5,857 bila di bandingkan dengan peran serta institusi yang tidak ada. 


\section{Hubungan Tindakan Penyehatan ALat Angkut Dengan Tingkat Risiko Kesehatan Kapal \\ Dari 3 orang ABK yang} menyatakan tidak pernah dilakukan tindakan penyehatan alat angku, selurunya 100\% memiliki tingkat risiko kesehatan kapal yang tinggi. Dari 86 orang ABK yang menyatakan ada ada tindakan penyehatan alat angkut, 6 kapal (7,0\%) diantaranya memiliki tingkat risiko kesehatan kapal yang tinggidan 80 kapal (93,0\%) memiliki tingkat risiko kesehatan kapal yang rendah.

Tindakan penyehatan alat angkut yang dilakukan pada kapal yang di periksa pada umumnya adalah desinseksi yaitu tindakan penyehatan alat angkut yang dilakukan untuk mengendalikan atau membunuh vektor serangga yang menyebabkan penyakit pada manusia, yang terdapat pada bagasi, kargo, peti kemas dan alat angkut, sedangkan deratisasi yang dilakukan pada kapal atau alat angkut adalah untuk membunuh atau meniadakan tikus pada alat angkut, dengan melakukan penggasan Metil bromida kepada bagianbagian kompartemen kapal.

Tindakan hapus tikus di kapal merupakan salah satu bentuk tindakan sanitasi kapal, bahkan merupakan item penting dalam MDH. Salah satu pertanyaan dalam $\mathrm{MDH}$ adalah tentang adanya indikasi penyakit pes baik yang timbul diantara ABK maupun diantara tikus.Kepemilikan SSCEC juga sangat memperhatikan Surat Keterangan Hapus Tikus (SKHT), artinya bahwa kepemilikan SSCEC mutlak harus memperhatikan sanitasi kapal secara keseluruhan. ${ }^{5}$

Hasil uji statistik dengan menggunakan uji chi-square diperoleh bahwa nilai $\mathrm{p}=0.001(\mathrm{p}<0,05)$ hal ini menunjukkan bahwa ada hubungan antara tindakan penyehatan alat angkut dengan tingkat risiko kesehatan kapal dengan nilai OR $=.14,333$ artinya apabila pada alat angkut pernah dilaksanakan tindakan penyehatan alat angkut akan memiliki tingkat risiko kesehatan kapal yang rendah sebesar 14,333 bila di bandingkan pada alat angkut yang tidak pernah dilakukan tindakan penyehatan alat angkut.

\section{Analisis Multivariat}

Tabel analisis multivariat menunjukkan bahwa faktor yang paling dominan berhubungan dengan tingkat risiko kesehatan kapal adalah faktor penerapan SOP dengan nilai $\mathrm{p}=0,002$ dan nilai $\mathrm{OR}=66,61$ dan diikuti dengan faktor Peran Serta Institusi dengan nilai $p=0,020$ dan niali OR = 29,15.

Tingkat sanitasi pada kapal-kapal yang sandar di pelabuhan Pangkalbalam masih rendah. Standar prosedur operasional, $(\mathrm{OR}=98,3)$, kepemimpinan nahkoda $(\mathrm{OR}=22,7)$ dan waktu yang digunakan untuk peningkatan sanitasi kapal $(\mathrm{OR}=24,1)$, secara signifikan berhubungan dengan tingkat sanitasi pada kapal yang sandar di pelabuhan Pangkalbalam. ${ }^{8}$

Penerapan SOP dalam penelitian ini adalah aplikasi panduan atau peraturan yang dilaksanakan dalam bidang sanitasi kapal oleh nahkoda dan anak buah kapal.Artinya penerapan SOP mencakup ada atau tidaknya kapal tentang SOP yang berhubungan dengan upaya sanitasi kapal.Salah satu upaya untuk meningkatkan sanitasi kapal adalah melakukan pengelolaan sampah kapal dengan menetapkan SOP pengelolaan sampah.Pada kapal penumpang perlu diciptakan sanitasi kapal yang benar, selain itu perlu pemenuhan indikator sanitasi lainnya seperti penyediaan air bersih, dan pengendalian vektor atau rodent.Penerapan SOP dalam penelitian ini adalah aplikasi panduan atau peraturan yang dilaksanakan dalam bidang sanitasi kapal oleh nahkoda dan anak buah kapal.Artinya penerapan SOP mencakup ada atau tidaknya kapal tentang SOP yang berhubungan dengan upaya sanitasi kapal.

\section{Kesimpulan}

Dari hasil penelitian dapat disimpulkan bahwa terdapat hubungan 
antara pengetahuan, penerapan SOP, kepemimpinan nahkoda, peran serta institusi KKP dan tindakan penyehatan alat angkut $\mathrm{ABK}$ dengan tingkat risiko kesehatan kapal. Penerapan SOP merupakan faktor yang sangat dominan berhubungan dengan tingkat risiko kesehatan kapal dengan $\mathrm{OR}=66$,

\section{Saran}

Kepada Kantor Kesehatan Pelabuhan (KKP) Kelas I Medan agar melaksanakan sosialisasi dan koordinasi dengan pihak PT. Pelayaran/Pemilik kapal, ABK tentang Sanitasi Kapal dan dampak sanitasi alat angkut dengan risiko tinggi. Kepada Pemilik Kapal agar menyediakan SOP sanitasi kapal sebagai pedoman bagi ABK dan nahkoda kapal untuk menciptakan sanitasi kapal yang benar. Kepada Nahkoda Kapal agar melaksanakan pengawasan terhadap pelaksanaan penerapan SOP sanitasi kapal, baik secara rutin maupun pengawasan secara mendadak, sekaligus memberikan sanksi terhadap ABK yang tidak melaksanakan SOP sanitasi kapal dengan benar seperti penambahan jadwal jaga maupun tindakan aplikatif lainnya yang dapat merubah perilaku ABK.

\section{Daftar Pustaka}

1. World Helath Organization. International Medical Gaide for Ship. Edisi ke II, Switzerland; 2005.

2. World Helath Organization. Global Burden of Stroke World Health Organization; 2007.

3. Departemen Kesehatan Indonesia. Peraturan Menteri Kesehatan No.356/Menkes/Per/IV/2008 tentang Organisasi dan Tata Kerja Kantor Kesehatan Pelabuhan. Jakarta; 2008.

4. Supriyadi. Faktor yang berhubungan dengan Tingkat Sanitasi pada Kapal yang Bersandar di Pelabuhan Pangkalan Balam Pangkalan Pinang tahun 2005. Jurnal Makara Kesehatan 10 (2); 2006.

5. Soejudi H. Pengendalian Rodent Suatu Tindakan Karantina. Jurnal Kesehatan Lingkungan, Vol 2; 2005.

6. Adriyani. Manajemen Sanitasi Pelabuhan Domestik. Jurnal Kesehatan Lingkungan Volume 2; 2005.

7. Notoadmodjo S. Pengembangan Sumber Daya Manusia. Jakarta: Rineka Cipta; 2010.

8. Elaine $\mathrm{H}$ Cramer. Sanitation Inspection On Cruise Ships 1990-2005 Vessel Sanitation Program, Centers for Disease Control and Prevention. Jurnal of Envoronmental Health, March 2008. 